\title{
A Review on Ontology Development Methodologies for Developing Ontological Knowledge Representation Systems for various Domains
}

\author{
Enesi Femi Aminu \\ Department of Computer Science, Federal University of Technology Minna, Nigeria \\ Email: enesifa@futminna.edu.ng \\ Ishaq Oyebisi Oyefolahan \\ Department of Information \& Media Technology, Federal University of Technology Minna, Nigeria \\ Email: o.ishaq@futminna.edu.ng \\ Muhammad Bashir Abdullahi \\ Department of Computer Science, Federal University of Technology Minna, Nigeria \\ Email: el.bashir02@futminna.edu.ng \\ Muhammadu Tajudeen Salaudeen \\ Department of Crop Production, Federal University of Technology Minna, Nigeria \\ Email: mtsalaudeen@futminna.edu.ng
}

Received: 06 June 2019; Accepted: 17 November 2019; Published: 08 April 2020

\begin{abstract}
The success of machine represented web known as semantic web largely hinges on ontologies. Ontology is a data modeling technique for structured data repository premised on collection of concepts with their semantic relationships and constraints on domain. There are existing methodologies to aid ontology development process. However, there is no single correct ontology design methodology. Therefore, this paper aims to present a review on existing ontology development approaches for different domains with the goal of identifying individual methodology's weakness and suggests for hybridization in order to strengthen ontology development in terms of its content and constructions correctness. The analysis and comparison of the review were carried out by considering these criteria but not limited to: activities of each method, the initial domain of the methodology, ontology created from scratch or reuse, frequently used ontology management tools based on literature, subject granularity, and usage across different platforms. This review based on the literature showed some approaches that exhibit the required principles of ontology engineering in tandem with software development principles. Nonetheless, the review still noted some gaps among the methodologies that when bridged or hybridized a better correctness of ontology development would be achieved in building intelligent system.
\end{abstract}

Index Terms - Ontology, domain, methodology, intelligent system, semantic web

\section{INTRODUCTION}

Web of knowledge popularly known as semantic web has attracted research attentions over some decades. Semantic web, technically denoted as web 3.0 and which can be simply described as web of meaning [1] does not exist in parallel with the existing web (web 2.0) but would gradually evolves from it [2]. The existing web is not machined understandable and therefore not in cooperation with users especially as regards precise information retrieval. However, semantic web promises cooperation between people and machines $[3,4,5]$. Therefore, in order to achieve this promising trend, a prime technology called ontology becomes indispensible [6]. Semantic web and Ontologies are promising technology outlined for knowledge modeling and capable of inference for designing intelligent systems $[7,8]$.

Technically, based on the field of Computer Science, ontology is a logical theory that is normally encoded using knowledge representation languages such as, First Order Logic (FOL), very popular Web Ontology Language (OWL) [9]. Ideally, Ontology is a data modeling technique for structured data repository 
premised on collection of concepts with their semantic relationships and constraints on a chosen area of knowledge (domain). The real power of ontologies lies in its ability to build relationships among classes and instances, and to assign properties to those relationships that enable inferences $[10,11,12]$. Similarly, one of the popular definitions of ontology $[13,14]$ is that of [15] which states that ontology is an explicit and formal specification of a conceptualization. The term "explicit" means the concepts and constraints of the real-life scenario are clearly defined. The term "formal" stresses the fact that ontology is all about a structured repository, in order words machine understandable. The term "conceptualization" denotes abstract model of a real-life scenarios through which appropriate concepts are identified.

The real-life scenarios may be agriculture, medicine, sports, religion, arts and entertainment and the rest. These scenarios are otherwise known as Domains [16,17]. Consequently, ontology is a shared understanding of some domain of interest which may be used as a unifying framework to solve problems of real-life situations [18]. The term "shared" is a notion that clearly shown that ontology is involved in the technique for solving a reallife problem. Furthermore, Ontology as a semantic model serves as a platform for accurate data integration and exchange. That is, ontologies have the capacity to address the problem of data inconsistency in a (distributed) system [19].

\section{Ontology Development}

Researchers used ontology to describe common vocabulary in any domain for information' sharing and reuse [20]. Besides, in order to achieve an inference based design for real-life scenarios, a comprehensive data model called ontology for standardizes terminologies is required [21]. It is also important to know the rationale behind ontology development. They are as follows: to share common understanding of the structure of information among people or software agents, to enable reuse of domain knowledge, to make domain assumptions explicit, to separate domain knowledge from the operational knowledge, and to analyze domain knowledge [22,23].

To develop ontology which is an iterative engineering process is actually tedious and time consuming [24] and expectedly, requires methodology like any software development. However, there is no standard methodology for developing ontology [25,26]. Similarly, [22] made it clear that there is no single correct ontology design methodology, hence which to follow is a matter of choice by the ontology developer. Nonetheless, in order to develop ontology that satisfy the principle of reusability and semantic-stability; activities such as predevelopment, development and post development must be duly considered [19]. Based on the sizeable numbers of literature duly reviewed in this paper, the popular methodologies used by developer include: Noy and McGuiness methodology, Gruninger and Fox's methodology, Methontology among others, NEON inclusive [27].

In addition to methods for developing ontology, ontology representation languages and editors (ontology management tools) also form part of the process of ontology development [28]. However, this review is limited to ontology development's methodologies because it serves as the bedrock of ontology development process. The choice of ontology management tools to implement the chosen method depends on the level of expressiveness for the proposed ontology. The ontology representation languages include OWL (both version 1 and 2) [29,30,31], RDF [32,33,34], RDF Schema

[35,36,37], DARPA Agent Markup Language and Ontology Interchange Language (DAML+OIL) [38,39] and the rest of them.

In this paper, we categorized these languages as World

Wide Web Consortium (W3C) standard while XML Topic Map (XTM) [40]- another ontology language is categorized as Standardization for International Organization (ISO) standard. Among the W3C standard language, OWL is reportedly most popular because of its expressiveness $[32,41,42]$. The ontology editor tools also include Protégé $[43,44,45,46]$, FAO AGROVOC Concept Server Workbench Tool [47,48]; OBO-Edit [49,50]; SWOOP [51,52]; Apollo [53,54]; IsaViz [55,56]; TopBraidComposer [57,58] and citrus ontology developed from scratch using Gruff on AllegroGraph [59]

However, it is important to mention that the prime objective of this review is to analyze and compare the activities of the existing ontology development methodologies based on some significant criteria. Such as, activities of each method, the initial domain where the methodology was adopted, subject granularity and usage across different platforms. And at the end, achieve the goal of identifying individual methodology's weakness and suggests for hybridization in order to strengthen ontology development in terms of its content and constructions correctness.

\section{LITERATURE REVIEW: ONTOLOGY DEVELOPMENT METHODOLOGY}

In this section, the methodologies for ontology development are reviewed. Methodologies indicate set of guiding principles on how the identified activities in the process of ontology design are duly carried out. Hence, the needs to develop ontology based on existing or new methodologies cannot be overemphasis $[60,61]$. However, ontology developers are still confronted with the challenges of generic standard methods of building the knowledge representation owing to the inadequacies according to the standard required of software development guilding principles $[62,63]$. The Cyc project designed for creating sizeable knowledge-based systems was the first ontology development methodology recorded and published by [64]. The methodology is described in three stages [21]. 
Some of the methodologies have a long time standing history in ontology development. To this end, in the late twentieth century, [65] in their survey work examined some methodologies for developing ontology. They include TOVE (Toronto Virtual Enterprise) - an ontology engineering process of six approaches; Enterprise Model Approach which consist of four stages; Methontology consists of seven phases of engineering process; KBSI IDEF5 consists of five approaches. Others include SENSUS, MENELAS, ONIONS, Ontolingua and others. Similarly, [66] presented the most frequently used methodologies for ontology development. Methodologies presented includes Gruninger and Fox; Menthontology; Uschold and King; SENSUS. The author analyzes and compared these methods with the popular software development process called IEEE Standard 1074 - 1995.

Whenever the needs for ontology development occur, some pertinent questions from both ontology's engineers and domain experts concerning methodologies and other relevant ontology management tools call for attentions. This is because the correctness and consistency of ontology largely lies on its methodology which demands lot of experiences and skills. Questions such as, which methodologies mostly preferable to develop ontology from scratch or reuse existing ontologies and logical sequence of tasks to perform in the process of ontology development [67]. Conversely, [19] asserted in their work that the existing methodologies for ontology development fall short of comprehensive coverage for different activities, such as pre-development, development and post-development.

From literature, some ontologies are designed by combining the activities of two methods such as Methontology, Gruninger and Fox methodologies $[68,69,70]$.

Generally speaking, most ontology development methodologies is described as an iterative ontology engineering process in that, alteration or modification can be invoked upon at any stage of the process regardless of current stage of development. An iterative development process in the ontology engineering phase was followed to design domain based soccer ontology in the research work of [71]. Reference [72] in their bid to described an ontology development methodology based on ontology iterative process that would be incorporated with protégé, equally reported the existing famous approaches which includes Gruninger and Fox that again developed TOVE; Noy and McGuiness with example of wine ontology; Methontology of Fernandez, and Uschold and King.

During the process of ontology development $[73,74,75]$, there are three different strategies to identified ontology's concepts in any given domain [76]. These are: top-down, middle-out and bottom-up strategies. A topdown approach first identified the most abstract concepts and then, specialized into more specific concepts. A bottom-up approach first identified the most specific concepts and then generalized into more abstract concepts. While the middle-out approach, first identified the most important concepts and then generalized and specialized into other concepts [67]. The next sections specifically reviewed the following ontology development methodologies: Gruninger and Fox's methodology, Menthontology approach, Noy and McGuiness approach, Uschold and Kings Approach, and FAO-Based Approach.

\section{Gruninger \& Fox's Methodology}

It is a first-order-logic based method proposed by [77] to developed knowledge based systems (ontology). It is a formal method that draws the strength of classic logic. In that, it serves as a step to transform informal scenarios into formal languages. Its activities includes, identify motivating scenarios and formulize informal; specify terminology of the ontology within a formal language; set out the competency questions to determine the scope of the ontology; specify axioms and definitions for the terms in the ontology and establish conditions for characterizing the completeness of the ontology $[67,78,79,80]$. The method was initially designed to developed ontology under business enterprise related domain. But, today the method has been adopted across diverse of various fields of studies. For instance; [25] developed farmer- centric model (ontology) in agriculture domain to represent farmers' information needs in identified context for Sri Lanka farmers by adapting the technique of Gruninger \& Fox's methodology. OWL2-DL was used for implementation. Middle-out strategy was used to classify the main concepts of the ontology design. Also, the methodology formed an integral part of [81]'s University ontology.

A key aspect of this methodology has to do with its evaluation activity, referred to as set of Competency Questions (CQs) that aid in validating and checking the correctness of ontology design and equally to define the its scope. Use of formal modeling techniques is significant at this point $[82,83]$. More so, the method majorly form part of combined methodologies approach owing to this strength (that is, CQs) [68]. However, it was pointed out in the paper of [19] that considering level of coverage as criteria for this method (TOVE); it lacks support for ontology mapping and versioning. [68,84] also observed that the method do not have the capacity to provide complete details of the activities and techniques employed in them. More importantly, one of the core principles of ontology is reusability. It was observed that none of its activities represents the principle. However, the FAO-Based method provided for the reusability principle which is refer to as ontology evolution as post development activities into consideration.

\section{Methontology Methodology}

It was developed in the Artificial Intelligence Lab in Madrid for constructing ontologies either from scratch or reusing existing ontologies from ontology' servers. It was designed on webODE and ontoEdit as ontology management tool [21]. Initially, the approach was a consequent of the knowledge obtained from developing chemical ontology. The step-wise activities of the approach are: specification - where the aim of the ontology has to be identified, knowledge acquisition knowledge has to be extracted from different sources, 
conceptualization - domain terms as concepts or relations are identified; integration - super concepts either classes or properties are related to one another, implementation ontology representation language is required, evaluation and documentation $[85,86,87]$.

Reference [88] adopted the methodology to develop a Graduation Screen Ontology (GSO) and implemented by OWL-DL and Protégé. Similarly, [89] adopted the methodology to design ontology for Active Fall Protection System as domain. [90] validated the method and reported that it offers a clear and detailed systematic approach to ontology development method; whose activities supports and complies with software development life cycle. Although, [91] in their review affirmed that there is no generic standard for ontology development. However, the study revealed through the analyzes and comparison of some notable number of methodologies based on some criteria such as type of development, reusability support, strategies for identifying concepts remarked Methontology as outstanding method. [92] equally regarded it as popular and classic method.

The exceptional credit of Methontology is further affirmed in the work of [68] which described the activities of the method to be in full compliance with IEEE standard for software development process. Furthermore, frequently used methodologies for ontology development were reviewed in the research work of [93]. Among the approaches reviewed and compared are Uschold and King; Gruninger and Fox (who proposed another methodology called TOVE); Methontology and UPON by [94]. Finally, Methontology was adopted by the researchers for building the proposed semantic conflict detection ontology that exist between messages of web services. The choice of Methontology was influenced as a result of its development process which the authors claimed to be an IEEE standard 1074-1999.

Similarly, [95] claimed that Methontology is the best among others with detailed activities for development process. Nonetheless, the methodology is not without some notable shortcomings. For example; activity for carrying out evaluation at a pre-development stage lacks in Methontology but present in Gruninger and Fox.

\section{Noy and McGuiness Methodology}

Noy and McGuiness also an iterative method, is based on some fundamental rules. The method presented seven steps of developing ontology. They are as follows: determine the domain and scope of the ontology, consider reusing existing ontologies, enumerate important terms in the ontology, define the classes and the class hierarchy, define the properties of the classes, define the value of the slots and create instances [22]; [96,97]. The authors consistently used wine ontology to depict the methodology. [76] developed ontology for cash crop farmers' market in Nigeria where Noy-McGuiness method was employed owing to its simplicity. Top-down approach as strategy for identifying concepts was used. The ontology was developed and evaluated by protégé tool query and Export Tab plug-in using set of competency questions.[98] equally adopted the methodology to design their proposed ontology in software maintenance.

[99] adapted Noy-McGuiness and [100] to describe a six step development process to create antimicrobial prescription ontology and implemented it using ProtégéOWL. That is, the ontology is developed in the domain of antimicrobial-microorganism. Similarly, in the work of [101] the first four activities of Noy and McGuiness method were fused into the proposed ISI method to develop the ontology structure for the domain of natural disaster management.

\section{Uschold and King Methodology}

The method was conceived from the knowledge resulted from the development of enterprise ontology [18] The authors proposed four activities during the process of ontology development. These are: to identify the purpose of the ontology, to build the ontology, to evaluate ontology, and to document it. After a period of time, the method was enhanced via the proposed three strategies for identifying the main concepts in the ontology [102]. In addition to the enterprise ontology project using this method is also the development of Waste Water Ontology (WaWO) in the domain of waste water treatment [103].

\section{FAO-Based Methodology}

The FAO-Based method for ontology development proposed in the work of [104] is described in five phases. The paper reviewed ontology-based methods to construct agricultural knowledge management system and equally explore some of its key technologies. However, the existing popular methods were reported in the review not to have certification or recommendation and do not gain a wider acceptance. To this end, a method for agricultural ontology construction premised on the methods applied by Food and Agriculture Organization (FAO) for AGROVOC and AOS was proposed.

The method has the capacity to structure the functional description of domain ontology and equally determine and infer relation that exists between concepts. The authors reported that future research is needed for the implementation of the proposed framework. FAO of the United Nations is saddled with the responsibilities to curtails hunger and under nutrition. But, a very important activity like terminologies specification of ontology is equally not part of ontology design process of FAOBased method.

Besides these popular methodologies arose from literature which has earlier reviewed in these previous sections, the researchers tend to modify them and adapt to model various domains. For example, [105] presented a six step methodology in agricultural domain. [106] in their rice domain based ontology, proposed a five stage method. [107] in their work proposed a synthesized methodology for taxonomy design in the domain of construction contractual semantics. [108] presented a systematic methodology in which ontology in the domain of Intelligence Transportation Systems would be developed. [109] proposed a ten step-wise ontology 
development methodology labeled as Yet Another Methodology for Ontology (YAMO) for food domain. Similarly, [110] proposed also a ten step methodology to develop ontologies for two domains. Also, [111] in their research to develop ontology presented a two step methodology in the pattern of top down design approach.

More so, according to [112], comparison of some important ontology methodologies based on some criteria were carried out. Consequently, a methodology that hinges on the principles of Methontology was proposed to develop ontology based on multilingual terminology resources domain. In addition, [113] acknowledged the similarities that exist among numerous methodologies. These were combined into three major steps of ontology process to develop what is called Data Mining Optimization Ontology. In the case of [114], Unified Process for Ontology (UPON) and Methontology ontological methods were analyzed. Thus, it was reported that the former is the appropriate approach for developing their textile supply chain based ontology.

\section{RESEARCH METHODOLOGY}

The first motivation for this review was the fact that ontology is proving its strength as a model for complex knowledge representation which has to be achieved via established methodology. Ontology design without methodology as not expected in software engineering principle result to unethical practice called ontology hacking. Even though, there is no affirmatively correct ontology design methodology [23], system include that of ontology has to be designed based on certain approach. Therefore, this research aims to review ontology development methodologies considering their strengths and limitations based on literature and open them for further studies based on content analysis review method.

This paper considers a wide spectrum of publications related to ontology design methodologies, ontologies design for domain, modeling complex knowledge representation ontologically, ontology-based information retrieval techniques, ontology management tools and host of others via reliable online publications. Analysis of the literature is motivated by the pertinent theoretical insights and limitations of formal techniques in ontology design methodologies [19,91]. Methodologies' domains, subject granularity, ontology created from scratch or reuse and methodologies used across different platforms are some of the criteria considered for analysis.

\section{DISCUSSION}

Considering the literature reviewed in this paper, we categorized ontology development methodologies into two types: The Foundation ontology development methodologies and The Derivative ontology development methodologies. The former are the popular set of the methodologies which have been applied across different domains. They are described as basic methodologies which have yielded significant results in ontology development. Although, not without limitations. The latter are adapted methodologies for both generic and specific area of knowledge. The activities or phases of the Derivative ontology development approaches such as [11, 104,105] and FAO-Based are derived from the Foundation ontology development approaches just as the name implies.

More so, this paper considered three set of criteria for analysis. The criteria are functions of ontology's contents design correctness and metrics of evaluations as defined standards for software (ontology) engineering principles. They are listed as follows:

i. First Criteria - This set contain the initial domain of the methodology, current domain where methodologies are applied more frequently used ontology management (both ontology's editors and languages) tools for the methodologies and the strategy used for identifying ontology's concepts during development.

ii. Second Criteria - The second set of the criteria include ontology created from scratch or reuse, knowledge area (domain), ontology's language and editor, methodology and type of ontology language.

iii. Third Criteria - This is the last set of criteria. It includes subject granularity and methodologies used across different platforms (W3C and ISO).

Table1 presented the analysis of the foundation methodologies based on the reviews considering the initial and current domains where the methodologies were applied as part of the first criteria earlier mentioned.

Table 1. Analysis of the Foundation Ontology Development Methodologies

\begin{tabular}{|c|c|c|}
\hline Methodologies & $\begin{array}{c}\text { Initial Domain of } \\
\text { the Methodology }\end{array}$ & $\begin{array}{c}\text { Current Domain where } \\
\text { Methodology is } \\
\text { Applied }\end{array}$ \\
\hline Gruninger \& Fox & $\begin{array}{c}\text { Business Enterprise } \\
\text { Related Domain }\end{array}$ & Generic (Any Domain) \\
\hline Methontology & Chemical Ontology & Generic (Any Domain) \\
\hline $\begin{array}{c}\text { Noy and } \\
\text { McGuiness }\end{array}$ & Wine Ontology & Generic (Any Domain) \\
\hline $\begin{array}{c}\text { Uschold and } \\
\text { King }\end{array}$ & Enterprise Ontology & Generic (Any Domain) \\
\hline
\end{tabular}

As shown in the Table 1, the methodologies were applied to modeled ontology for the various initial domains. But presently so far from literature; they are used to model ontology for any domain. For example, Gruninger - Fox and Noy - McGuiness were used to modeled ontology in Agriculture domain [25,76] and Biomedical domain [99]. Waste Water Ontology (WaWO) was developed using Uscholds and King [103]. In addition, based on the number of literature where over One hundred high impacts articles were reviewed in this paper, it was discovered that middle-out approach appears to be more frequently used strategy for identifying ontology's concepts both in Methontology and Gruninger-Fox methologies. Top-down strategy was popular with Noy and McGuiness methodology. For 
Uschold and Kings Methodology, it cannot be clearly pointed out. It appears to be the least popular method out of the four. Similarly, out of the dozens of ontology management tools (both open-source and proprietary) available, OWL and Protégé are more used for implementing the methodologies by developers despite the fact that webODE and ontoEdit were designed for Methontology.

Furthermore, based on the reviewed literature; Table2 presented some ontologies modeled for various domains taken the second set of criteria into consideration.

Table 2. Analysis of Ontologies Design for Different Domains Based on the Second Criteria

\begin{tabular}{|c|c|c|c|c|c|}
\hline Literature & Domain & $\begin{array}{c}\text { Created from } \\
\text { Scratch or Reuse }\end{array}$ & Methodology & $\begin{array}{l}\text { Ontology's Language and } \\
\text { Editor }\end{array}$ & $\begin{array}{c}\text { Type of Ontology } \\
\text { Language }\end{array}$ \\
\hline $\begin{array}{l}\text { Anusha, et } \\
\text { al. (2015) } \\
{[25]}\end{array}$ & Farming & New & Gruninger \& Fox & OWL2-DL and Protégé & $\begin{array}{c}\text { Web Based Ontology } \\
\text { Langauge }\end{array}$ \\
\hline $\begin{array}{l}\text { Bonanci, et } \\
\text { al. (2016) } \\
\text { [105] }\end{array}$ & $\begin{array}{c}\text { Agriculture } \\
\text { (Reused of } \\
\text { SWEET and } \\
\text { Cuahsi } \\
\text { concepts) }\end{array}$ & Reused & Bonanci, et al & OWL2-DL and Protégé & $\begin{array}{l}\text { Web Based Ontology } \\
\text { Langauge }\end{array}$ \\
\hline $\begin{array}{c}\text { Aree et al } \\
(2009) \\
{[106]}\end{array}$ & Rice ontology & New & Aree et al & OWL and AGROVOC CS WB & $\begin{array}{l}\text { Web Based Ontology } \\
\text { Langauge }\end{array}$ \\
\hline $\begin{array}{l}\text { Wei et al, } \\
\text { (2012) [11] }\end{array}$ & $\begin{array}{c}\text { Agriculture } \\
\text { Pest Ontology }\end{array}$ & New & DSRM & OWL and Protégé 4.0 & $\begin{array}{c}\text { Web Based Ontology } \\
\text { Langauge }\end{array}$ \\
\hline $\begin{array}{l}\text { Godspower } \\
\text { and } \\
\text { Esingbemi } \\
(2016)[76]\end{array}$ & Cash Crop & New & $\begin{array}{c}\text { Noy and } \\
\text { McGuiness }\end{array}$ & OWL and Protégé & $\begin{array}{l}\text { Web Based Ontology } \\
\text { Langauge }\end{array}$ \\
\hline $\begin{array}{l}\text { Soner et al, } \\
\text { (2012) [71] }\end{array}$ & Soccer & New & Soner et al & OWL2-DL and Protégé & $\begin{array}{l}\text { Web Based Ontology } \\
\text { Langauge }\end{array}$ \\
\hline $\begin{array}{l}\text { Jianwei et } \\
\text { al, (2015) } \\
{[59]}\end{array}$ & $\begin{array}{c}\text { Agriculture } \\
\text { (Citrus } \\
\text { ontology) } \\
\end{array}$ & New & Jianwei et al & $\begin{array}{l}\text { RDF/S, Gruff and } \\
\text { TopBraidComposer }\end{array}$ & Web Standard language \\
\hline $\begin{array}{c}\text { Tiffani et } \\
\text { al, (2012) } \\
{[99]}\end{array}$ & $\begin{array}{c}\text { Antimicrobial- } \\
\text { Microorganis } \\
\mathrm{m}\end{array}$ & New & $\begin{array}{l}\text { Noy-McGuiness } \\
\text { and Arp }\end{array}$ & OWL and Protégé & $\begin{array}{c}\text { Web Based Ontology } \\
\text { Langauge }\end{array}$ \\
\hline $\begin{array}{l}\text { Jinsoo et al, } \\
(2008)[88]\end{array}$ & $\begin{array}{c}\text { Graduation } \\
\text { Screen } \\
\text { Ontology } \\
\text { (GSO) } \\
\end{array}$ & New & Methontology & OWL-DL and Protégé & $\begin{array}{l}\text { Web Based Ontology } \\
\text { Langauge }\end{array}$ \\
\hline $\begin{array}{c}\text { Rizwan and } \\
\text { Aida (2013) } \\
\text { [68] }\end{array}$ & $\begin{array}{l}\text { Quran } \\
\text { Ontology }\end{array}$ & New & $\begin{array}{l}\text { Gruninger \& Fox } \\
\text { and Methontology }\end{array}$ & OWL-DL and Protégé & $\begin{array}{c}\text { Web Based Ontology } \\
\text { Langauge }\end{array}$ \\
\hline
\end{tabular}

From Table2, different methodologies were used to model ontologies for various domains. For instance, while Gruninger-Fox, Methontology, Noy-McGuiness methodologies were adopted; [59,106] were also adapted. In the same vein, some developers chose to merge two methodologies to design ontology for example, Gruninger and Fox and Methontology [83,90,91,93]. In order to show that ontology is still an evolving area of study, from the literatures, ontologies are often created from scratch and OWL is described as Web Based Ontology Language [115].

Finally in this section, Table3 presents ontology development methodologies based on subject granularity and usage across different platforms (W3C and ISO) as the third criteria.

Table 3. Comparison of Ontology Development Methodologies Based on the Third Criteria

\begin{tabular}{|c|c|c|c|c|}
\hline \multirow[t]{2}{*}{ Methodology } & \multirow[t]{2}{*}{ Subject Granularity } & \multicolumn{2}{|c|}{ W3C Standard } & \multirow{2}{*}{$\begin{array}{c}\begin{array}{c}\text { ISO } \\
\text { Standard }\end{array} \\
\text { XTM } \\
\end{array}$} \\
\hline & & RDF/RDFS & OWL & \\
\hline Gruninger and Fox & $\begin{array}{l}\text { Set out the competency questions to determine the scope } \\
\text { of the ontology }\end{array}$ & less frequent & more frequent & infrequent \\
\hline Methontology & Specification & less frequent & more frequent & infrequent \\
\hline Noy and McGuiness & Determine the domain and scope of the ontology & less frequent & more frequent & infrequent \\
\hline Uschold and King & To identify the purpose of the ontology & less frequent & less frequent & infrequent \\
\hline FAO-Based & Determination of ontology purpose and scope & less frequent & more frequent & infrequent \\
\hline
\end{tabular}


Ontology developer must ensure to precisely and explicitly define the subject granularity. Subject Granularity depicts scope [116]. It specifies a well defined scope of ontology's domain. Achieving this goal would definitely enhance ontology's correctness. For instance, ontology's domain proposed to be agriculture, may be further defined to be crop - cereal or tuber of a crop, maize, maize's disease, or a precise aspect or characteristic of a maize. This criterion is very significant in ontology development. It is described as precautionary measure because it disambiguates ontology's domain and ensure a valid knowledge representation model. This in turn produces a precise ontology which enhances semantic annotation for ontology-based information retrieval. However, a technique may be established to achieve this criterion.

Therefore, from Table3 each methodology has its own activity to define subject granularity. But it was reported that Gruninger and Fox mostly used a mathematical model (First-Order-Logic or Description Logic) to validate its competency questions in order to strongly establish the purpose and scope of ontology's domain. More so, on these criteria set, we look at the frequencies of applying ontology language (RDF/S, OWL and XTM) for implementing the methodologies. The following keys were used to present what we discovered during the course of literature review.

- more frequent - meaning it is more frequently used by ontology developers or researchers

- $\quad$ less frequent - meaning it is fairly (less frequently) used compared to other methods

- $\quad$ infrequent - meaning it is rarely (not frequently) used

In conclusion of this section, this review further proposes a hybridization of Gruninger and Fox, Methontology and FAO-Based methodologies as represented by Fig.1. This is to strengthen their limitations by combining activities in compliance with [19] recommendation while modeling ontology.

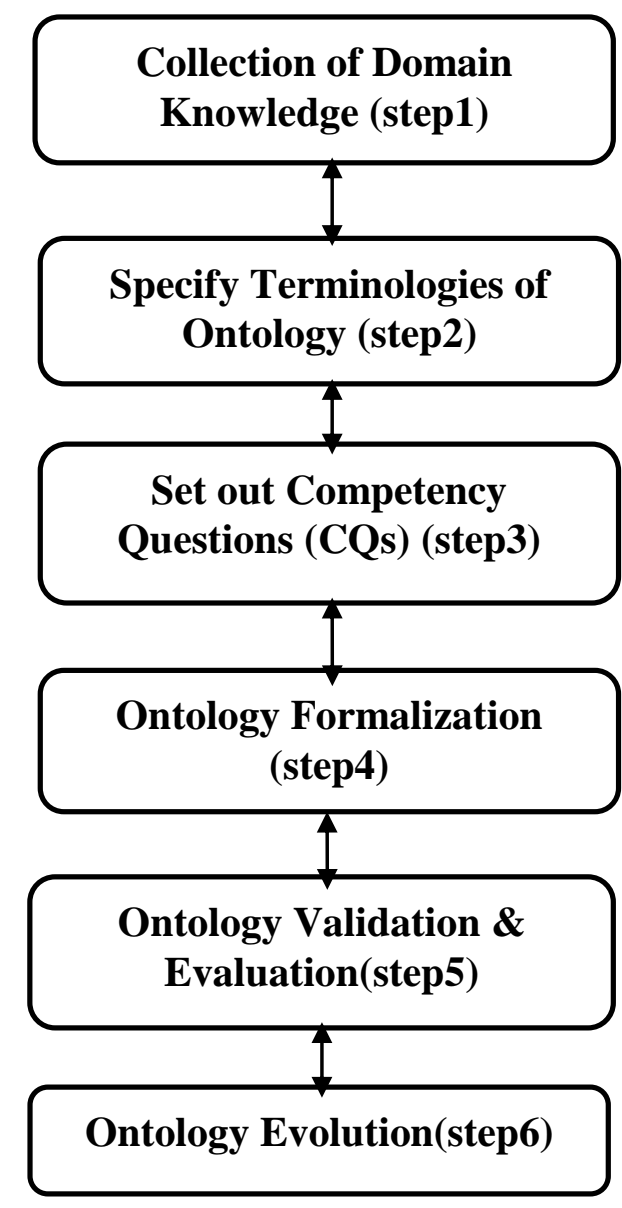

Fig.1. Proposed Ontology Development Methodology

Activities or steps 1 to 3 that is, collection of domain information, specification of ontology's terminologies and setting competency questions satisfy the predevelopment recommendation. Ontology formalization and ontology validation or evaluation activities satisfy the development stage. And the ontology evolution satisfies the post-development recommendation. Furthermore, Table4 presented a comparative analysis that depicts the relationship of the proposed method against the existing frequent methodologies considering the required recommendation and standard of developing ontology according to [19].

Table 4. Relationship of the proposed method against the existing methodologies

\begin{tabular}{|c|c|c|c|c|c|c|}
\hline \multirow[t]{2}{*}{ Methodologies } & \multicolumn{3}{|c|}{ Pre-Development Activities } & \multicolumn{2}{|c|}{ Development } & \multirow{2}{*}{$\begin{array}{c}\text { Post- } \\
\text { Development } \\
\text { Activities } \\
\text { Ontology } \\
\text { Evolution }\end{array}$} \\
\hline & $\begin{array}{c}\text { Collectio } \\
\text { n and } \\
\text { Analysis } \\
\text { of } \\
\text { Domain } \\
\text { Informati } \\
\text { on }\end{array}$ & $\begin{array}{l}\text { Specification of } \\
\text { Ontology's } \\
\text { Terminologies }\end{array}$ & $\begin{array}{c}\text { Setting of } \\
\text { Competency } \\
\text { Questions (Using } \\
\text { Logics ) }\end{array}$ & $\begin{array}{c}\text { Ontology } \\
\text { Formalizatio } \\
\mathbf{n}\end{array}$ & $\begin{array}{c}\text { Ontology } \\
\text { Evaluation }\end{array}$ & \\
\hline Gruninger-Fox & $\checkmark$ & $\checkmark$ & $\checkmark$ & $\checkmark$ & $\checkmark$ & $x$ \\
\hline Methontology & $\checkmark$ & $\checkmark$ & $x$ & $\checkmark$ & $\checkmark$ & $\checkmark$ \\
\hline FAO-Based & $\checkmark$ & $x$ & $x$ & $\checkmark$ & $\checkmark$ & $\checkmark$ \\
\hline $\begin{array}{l}\text { Proposed } \\
\text { Hybridized } \\
\text { Approach }\end{array}$ & $\checkmark$ & $\checkmark$ & $\checkmark$ & $\checkmark$ & $\checkmark$ & $\checkmark$ \\
\hline
\end{tabular}


Keys:

Denotes activity explicitly present in the methodology

× Denotes activity not explicitly present

\section{SUMMARY AND CONCLUSION}

This paper reviews the ontology development methodologies for designing and implementing ontology as a complex knowledge representation model for any knowledge area (domain) by ontology researchers and developers. This research work, categorized the methodologies into two types. They are: Foundation and Derivative methodologies. For example, Gruninger-Fox and FAO-Based methods are categorized as foundation and derivative respectively. Tools (such as Protégé, Apollo, OWL, RDF, XTM) for implementing the methodologies were briefly analyzed and compared. The paper presented three categories of criteria for analysis and comparisons.

The first analysis took into consideration four criteria. These are: the initial domain of the methodology, current domain where methodologies may be applied, frequently used ontology management tools (both ontology's editors and languages) for the methodologies and strategy for identifying ontology's concepts during development. The second comparison and analysis took into consideration five criteria. Namely, ontology created from scratch or reuse, knowledge area, ontology's language and editor, methodology and type of ontology language. And the third analysis considered two criteria. They as follows: subject granularity and usage across different platforms. Subject granularity among other criteria considered in this research is significant. Similarly, the review paper classifies the ontology representation languages into two standards: the W3C and ISO standards.

In conclusion, Gruninger and Fox, Methontology, Noy and McGuiness include FAO-Based methodologies have demonstrated potentials for ontology development however, not without limitations which call for research attention. For example, subject granularity of proposed domain have to be clearly defined if ontology correctness and validity should not be compromised or trade off. In this work, we suggest that agriculture for instance, should not be a defined subject for domain owing to its broadness and undoubtedly, vast of its inexhaustible knowledge or data. A particular domain can still be broken down into some granules, model ontologically and finally merge if necessary for further work. Similarly, OWL is highly explored when implementing methodologies among its contemporaries. This is owing to its expressivity in terms of concepts' relations and axioms. This fact is verified by over one hundred literature we considered in this review. In contrast, XTM has a low application. Nonetheless, this research brings to the attention of ontology developers that the ontology development methodologies along with knowledge representation languages presented and reviewed in this paper are cross platform. That is, they may be implemented in any (W3C or ISO) standard.
Based on the review, conclusion is equally drawn that ontology is still an evolving area of study so also its technologies. Despite the hundreds of existing ontologies; most developers still create new ontology from scratch despite its tediousness. This equally serves as a call for research attention in the area of ontology mapping and population. More so, we suggest in this paper as a matter of further study that the problem of domain or subject granularity definition owing to natural languages ambiguities or word mismatch can be handled by considering enhancement to the existing semantic databases. For example, WordNet can be improved as a result of its limitation in senses return of word inflected forms. AGROVOC is another database for agriculture domain. All these can assist in synonyms or polysemous concepts of domain. Thereby, increases the correctness and validity of ontology design.

\section{ACKNOWLEDGEMENT}

This review work was performed as part of a PhD Thesis at the Federal University of Technology, Minna and funded via Award of TETFUND Institution-Based Research Intervention (IBRI) Fund with Grant TETFUND/FUTMINNA/2016-2017/6 ${ }^{\text {th }}$ $\mathrm{BRP} / 04$.

\section{REFERENCES}

[1] Hitzler, P., \& Janowicz, K. (2013). Linked Data, Big Data, and the 4th Paradigm. Semantic Web, 4(3), 233-235

[2] Grigoris, A. \& Frank-van, H. (2008). A Semantic Web Primer. The MIT Press Cambridge, Massachusetts London, England.

[3] Ashraf, J., Chang, E., Hussain, O. K., \& Hussain, F. K. (2015). Ontology usage analysis in the ontology lifecycle: A state-of-the-art review. Knowledge-Based Systems, 80, 34-47.

[4] Noh, Y. (2015). Imagining library 4.0: creating a model for future libraries. The Journal of Academic Librarianship, 41(6), 786-797

[5] Pan, Y. (2016). Heading toward artificial intelligence 2.0. Engineering, 2(4), 409-413.

[6] Wang, W., De, S., Cassar, G., \& Moessner, K. (2013). Knowledge representation in the internet of things: semantic modelling and its applications. automatika, 54(4), 388-400.

[7] Ramos, L. (2015). Semantic Web for manufacturing, trends and open issues: Toward a state of the art. Computers \& Industrial Engineering, 90, 444-460

[8] Pattuelli, M. C., Provo, A., \& Thorsen, H. (2015). Ontology building for linked open data: A pragmatic perspective. Journal of Library Metadata, 15(3-4), 265294

[9] Sanfilippo, E. M., \& Borgo, S. (2016). What are features? An ontology-based review of the literature. ComputerAided Design, 80, 9-18.

[10] Thomas C. J. (2009) 'Just what is an ontology, anyway?' IT Professional, 11, 22-27.

[11] Wei Y., Wang, R. Hu, Y. \& Wang, X. (2012). From Web Resources to Agricultural Ontology: a Method for SemiAutomatic Construction'Journalof Integrative Agriculture, 11(5): 775-783

[12] Meriyem, C., Adil, S., \& Hicham, M. (2015). IT Governance ontology building process:example of developing audit ontology. International Journal of Computer Techniques, 2(1), 134-141. 
[13] Ivanović, M., \& Budimac, Z. (2014). An overview of ontologies and data resources in medical domains. Expert Systems with Applications, 41(11), 5158-5166

[14] Barão, A., de Vasconcelos, J. B., Rocha, Á., \& Pereira, R. (2017). A knowledge management approach to capture organizational learning networks. International Journal of Information Management, 37(6), 735-740.

[15] Gruber, T. R. (1993). A Translation Approach to Portable Ontology Specifications. Knowledge Acquisition, 5(2): 199-220

[16] Dou, D., Wang, H., \& Liu, H. (2015, February). Semantic data mining: A survey of ontology-based approaches. In Semantic Computing (ICSC), 2015 IEEE International Conferenc on (pp. 244-251). IEEE

[17] Kang, Y. B., Haghighi, P. D., \& Burstein, F. (2014). CFinder: An intelligent key concept finder from text for ontology development. Expert Systems with Applications, 41(9), 4494-4504

[18] Uschold, M., \& King, M. (1995). Towards a Methodology for Building Ontologies. In IJCAI95 Workshop on Basic Ontological Issues in Knowledge Sharing. Montreal

[19] Dnyanesh, R. \& Rahul, C. A (2011). Generic ontology development framework for data integration and decision support in a distributed environment. International Journal of Computer Integrated Manufacturing Vol. 24, No. 2, 154-170

[20] Pratibha, G., Sangeeta, D. \& Bhanumurthy, K. (2011). Ontology Development Methods. DESIDOC Journal of Library \& Information Technology, Vol. 31, No. 2, pp. $77-83$

[21] Agyapong-Kodua, K., Niels, L., Robert, D., \& Svetan, R. (2013) 'Review of semantic modeling technologies in support of virtual factory design' International Journal of Production Research, Vol. 51, No. 14, 4388-4404

[22] Noy, N. F. and McGuinness, D. L. (2001) 'Ontology Development 101: A guide to Creating Your First Ontology', Stanford University, Stanford, CA, USA, pp. $1-25$.

[23] Noy, N. F., \& McGuinness, D. L. (2016). Ontology development 101: a guide to creating your first ontology Stanford University.

[24] Alexander, C. Y. (2006). Methods in biomedical ontology. Journal of biomedical informatics, 39(3), 252-266

[25] Anusha, I. W., Athula G., \& Gihan, N. W. (2015) 'User centered ontology for SriLanka farmers' Ecological Informatics, 140-150

[26] Bhaskar, K. \& Savita S. (2010) 'A Comparative Study Ontology Building Tools for Semantic Web Applications' International journal of Web \& Semantic Technology (IJWesT) Vol.1, Num.3, July 2010 DOI 10.5121/ijwest.2010.1301 1

[27] Ast, M., Glas, M., Roehm, T., \& Luftfahrt, V. B. (2014). Creating an ontology for aircraft design. Deutsche Gesellschaft für Luft-und Raumfahrt-Lilienthal-Oberth eV

[28] Munir, K., \& Anjum, M. S. (2018). The use of ontologies for effective knowledge Modeling and information retrieval. Applied Computing and Informatics, 14(2), 116126

[29] Bechhofer, S. (2009) "OWL: Web ontology language." Encyclopedia of database systems. Springer, Boston, MA, 2009. 2008-2009

[30] Richard F., Patrick H., \& Ian H. (2004). OWL-QL-a language for deductive query answering on the Semantic Web. Web Semantics: Science, Services and Agents on the World Wide Web 2 19-29

[31] Cardoso, J., \& Pinto, A. M. (2015). The Web Ontology Language (OWL) and its Applications. In Encyclopedia of
Information Science and Technology, Third Edition (pp. 7662-7673). IGI Global

[32] Sengupta, K., \& Hitzler, P. (2014). Web ontology language (OWL). Encyclopedia of Social Network Analysis and Mining, 2374-2378.

[33] Arenas, M., Grau, B. C., Kharlamov, E., Marciuška, Š., \& Zheleznyakov, D. (2016). Faceted search over RDF-based knowledge graphs. Journal of Web Semantics, 37, 55-74

[34] Calbimonte, J. P., Mora, J., \& Corcho, O. (2016, May). Query rewriting in RDF stream processing. In European Semantic Web Conference (pp. 486-502). Springer, Cham

[35] Jeen B., Michel K., Stefan D., Dieter F., Frankvan H., \& Ian H. (2002). Enabling knowledge representation on the Web by extending RDF Schema. Computer Networks 39 609-634

[36] Khan, J. A., \& Kumar, S. (2014, October). Deep analysis for development of RDF, RDFS and OWL ontologies with protege. In Proceedings of $3 r d$ International Conference on Reliability, Infocom Technologies and Optimization (pp. 1-6). IEEE

[37] Schenner, G., Bischof, S., Polleres, A., \& Steyskal, S. (2014, September). Integrating Distributed Configurations With RDFS and SPARQL. In Configuration Workshop (Vol.1220, pp. 9-15)

[38] Rodríguez, N. D., Cuéllar, M. P., Lilius, J., \& CalvoFlores, M. D. (2014). A survey on ontologies for human behavior recognition. ACM Computing Surveys (CSUR), 46(4), 43

[39] Slimani, T. (2015). Ontology development: A comparing study on tools, languages and formalisms. Indian Journal of Science and Technology, 8(24), 1-12

[40] Enesi, F. A. \& Adewale, O. S. (2015) 'A Mechanism for Detecting Dead URLs in XTM-Based Ontology Repository' International Journal of Computer Applications (0975 - 8887) Volume 111 - No 12

[41] Carroll, J., Herman, I., \& Patel-Schneider, P. F. (2015). OWL 2 web ontology language RDF-based semantics. W3C Recommendation (October 27, 2009)

[42] Hacherouf, M., Bahloul, S. N., \& Cruz, C. (2015). Transforming XML documents to OWL ontologies: A survey. Journal of Information Science, 41(2), 242-259

[43] John, H. G., Mark, A. M., Ray, W. F., Williams, E. G., Monica, C., Henrik, E., Natalya, F. N. \& Samson W. T. (2003). The evolution of Protégé: an environment for knowledge-based systems development. International Journal of Human-Computer Studies, Vol. 58, Issue1, Pages $89-123$

[44] Chujai, P., Kerdprasop, N., \& Kerdprasop, K. (2014). On transforming the ER model to ontology using protégé OWL tool. International Journal of Computer Theory and Engineering, 6(6), 484

[45] Wohlgenannt, G., Sabou, M., \& Hanika, F. (2016). Crowd-based ontology engineering with the uComp Protégé plugin. Semantic Web, 7(4), 379-398

[46] Yadav, U., Narula, G. S., Duhan, N., Jain, V., \& Murthy, B. K. (2016). Development and visualization of domain specific ontology using protege. Indian Journal of Science and Technology, 9(16), 1-7

[47] Panita, Y., Dussadee, T., Thanapat, S., Asanee, K., Sachit, R., Margherita, S., \& Johannes K. (2008). The AGROVOC Concept Server Workbench: A Collaborative Tool for Managing Multilingual Knowledge. World Conference on Agricultural Information and IT

[48] Stellato, A., Turbati, A., Fiorelli, M., Lorenzetti, T., Costetchi, E., Laaboudi, C., \& Keizer, J. (2017, September). Towards VocBench 3: pushing collaborative development of thesauri and ontologies further beyond. In 
17th European Networked Knowledge Organization Systems Workshop, NKOS 2017 (Vol. 1937, pp. 39-52). CEUR-WS

[49] John D., Midori A. H., Melissa Haendel \& Suzanna L. (2007). OBO-Edit-an ontology editor for biologists. Bioinformatics, Volume 23, Issue 16, 15, Pages 21982200

[50] Mungall, C. J., Dietze, H., \& Osumi-Sutherland, D. (2014). Use of OWL within the Gene Ontology. BioRxiv, 010090

[51] Aditya, K., Bijan, P., Evren, S., Bernardo, C. C. \& James, H. (2006) 'Swoop: A Web Ontology Editing Browser' Web Semantics: Science, Services and Agents on the World Wide Web Vol. Issue 2, 144-153

[52] Khan, Z. C., \& Keet, C. M. (2015). An empirically-based framework for ontology modularisation. Applied Ontology, 10(3-4), 171-195

[53] Emhimed A. (2013). Comparison Some of Ontology Editors. Management Information Systems, Vol. 8, No. 2, pp. 018-024

[54] Hogan, W. R., Wagner, M. M., Brochhausen, M., Levander, J., Brown, S. T., Millett, N., \& Hanna, J. (2016) The Apollo Structured Vocabulary: an OWL2 ontology of Phenomena in infectious disease epidemiology and population biology for use in epidemic simulation. Journal of biomedical semantics, 7(1), 50.

[55] Mutton, P \& Golbeck, J. (2003). Visualization of semantic metadata and ontologies. Information Visualization, 2003. IV 2003. Proceedings. Seventh International Conference on. IEEE, 2003

[56] Anikin, A., Litovkin, D., Kultsova, M., Sarkisova, E., \& Petrova, T. (2017, September). Ontology visualization: Approaches and software tools for visual representation of large ontologies in learning. In Conference on Creativity in Intelligent Technologies and Data Science (pp. 133149). Springer, Cham

[57] Alatrish, E. S. (2013) "Comparison some of ontology." Journal of Management Information Systems 8.2 (2013): 018-024

[58] García-Peñalvo, F. J., Ordónez de Pablos, P., García, J., \& Therón, R. (2014). Using OWL-VisMod through a decision-making process for reusing OWL ontologies. Behaviour \& Information Technology, 33(5), 426-442.

[59] Jianwei, L., Li, L. \& Xiaoyan, L. (2015) 'An Integrated, Ontology-Based Agricultural Information System' Information Development, Vol. 31(2) 150-163

[60] Corcho, O., Fernández-López, M., \& Gómez-Pérez, A. (2003). Methodologies, tools and languages for building ontologies. Where is their meeting point?. Data \& knowledge engineering, 46(1), 41-64.

[61] Nanda, J., Simpson, T. W., Kumara, S. R., \& Shooter, S. B. (2006). A methodology for product family ontology development using formal concept analysis and web ontology language. Journal of computing and information science in engineering, 6(2), 103-113.

[62] Gavrilova, T. \& Gladkova, M. (2014). Big data structuring: the role of visual models and ontologies. Procedia Computer Science 31, 336 - 343

[63] Vigo, M., Bail, S., Jay, C., \& Stevens, R. (2014). Overcoming the pitfalls of ontology authoring: Strategies and implications for tool design. International Journal of Human-Computer Studies, 72(12), 835-845.

[64] Lenat, D. B., \& Guha, R. V. (1990). Building Large Knowledge-based Systems: Representation and Inference in the Cyc Project. Boston, MA: Addison-Wesley.

[65] Dean, J., Trevor, B. C. \& Pepijn V. (1998). Methodologies for Ontology Development. 62-75
[66] Fernandez-Lopez, M. Gomez-Perez, A., Pazos-Sierra, A., \& Pazos-Sierra, J. (1999) Building a chemical ontology using METHONTOLOGY and the ontology design environment', IEEE Intelligent Systems \& their applications 4 (1) 37-46

[67] Oscar C., Mariano F., and Asuncion G. (2003) 'Methodologies, tools and languages for building ontologies. Where is their meeting point?' Data \& Knowledge Engineering 46, 41-64

[68] Rizwan, I., \& Aida, M. (2013). An experience of developing Quran ontology with contextual information support. Multicultural Education \& Technology Journal Vol. 7 No. 4, pp. 333-343.

[69] Tan, H., Ismail, M., Tarasov, V., Adlemo, A., \& Johansson, M. (2016). Development and evaluation of a software requirements ontology. In 7 th International Workshop on Software Knowledge-SKY 2016 in conjunction with the 9th International Joint Conference on Knowledge Discovery, Knowledge Engineering and Knowledge Management-IC3K 2016, November 9-10, 2016, in Porto, Portugal (pp. 11-18). SciTePress.

[70] Zhou, Z., Goh, Y. M., \& Shen, L. (2016). Overview and analysis of ontology studies supporting development of the construction industry. Journal of Computing in Civil Engineering, 30(6), 04016026.

[71] Soner, K., Ozgur, A., Orkunt, S., Samet, A., Nihan, K. C. \& Ferda, N. A. (2012) 'Ontology-Based Retrieval System using Semantic Indexing' Information Systems 37, 294305

[72] Zhanjun L., Victor R. \& Karthik, R. (2007). A Methodology of Engineering Ontology Development for Information Retrieval. International Conference on Engineering Design, Iced 0728 - 31, Paris, France

[73] Obrst, L., Chase, P., \& Markeloff, R. (2012, October). Developing an Ontology of the Cyber Security Domain. In STIDS (pp. 49-56).

[74] Simperl, E., \& Luczak-Rösch, M. (2014). Collaborative ontology engineering: a survey. The Knowledge Engineering Review, 29(1), 101-131.

[75] Stojadinović, S. M., \& Majstorović, V. D. (2014). Developing engineering ontology for domain coordinate metrology. FME Transactions, 42(3), 249-255.

[76] Godspower, O. E. and Esingbemi, P. E. (2016). Ontology for Alleviating Poverty among Farmers in Nigeria. INFOS '16, May 09-11, 2016, Giza, Egypt

[77] Gruninger, M., \& Fox, M. S. (1995). Methodology for the Design and Evaluation of Ontologies. Workshop on Basic Ontological Issues in Knowledge Sharing, Montreal.

[78] Zainab, A. B. \& Khairul N. I. (2013). Base Durian Ontology Development Using Modified Methodology. Second International Multi-Conference on Artificial Intelligence Technology, M-CAIT Shah Alam.

[79] Hitzler, P., Gangemi, A., \& Janowicz, K. (Eds.). (2016). Ontology Engineering with Ontology Design Patterns: Foundations and Applications (Vol. 25). IOS Press.

[80] Kim, H. M., \& Laskowski, M. (2018). Toward an ontology - driven blockchain design for supply - chain provenance. Intelligent Systems in Accounting, Finance and Management, 25(1), 18-27.

[81] Hadjar, K. (2016). University Ontology: A Case Study at Ahlia University. In Semantic Web (pp. 173-183). Springer, Cham.

[82] Bilgin, G., Dikmen, I., \& Birgonul, M. T. (2018). An ontology-based approach for delay analysis in construction. KSCE Journal of Civil Engineering, 22(2), 384-398 
[83] El-Diraby, T. E. \& Osman, H. (2011). A domain ontology for construction concepts in urban infrastructure products. Automation in Construction 20, 1120-1132

[84] Gomez-Perez, A., Fernandez-Lopez, M. \& Corcho, O. (2004) 'Ontological Engineering: With Examples from the Areas of Knowledge Management, e-Commerce and the Semantic Web', Springer Science \& Business Media, 2006.

[85] Hafedh, N., Mohamed, F., Imed R. F. \& Basel S. (2014). A Critical Analysis of lifecycles and Methods for Ontology Construction and Evaluation' 1st International Conference on Advanced Technologies for Signal and Image Processing - ATSIP'2014

[86] Haghighi, P. D., Burstein, F., Zaslavsky, A., \& Arbon, P. (2013). Development and evaluation of ontology for intelligent decision support in medical emergency management for mass gatherings. Decision Support Systems, 54(2), 1192-1204.

[87] Janowicz, K. (2012). Observation - driven geo - ontology engineering. Transactions in GIS, 16(3), 351-374.

[88] Jinsoo, P., Kimoon, S., \& Sewon, M. (2008). Developing Graduation Screen Ontology based on the METHONTOLOGY Approach. Fourth International Conference on Networked Computing and Advanced Information Management.

[89] Guo, B. H., \& Goh, Y. M. (2017). Ontology for design of active fall protection systems. Automation in Construction, 82, 138-153.

[90] Noman, I., Abu, Z. A. and Zubair, A. S. (2010) 'Semantic Web: Choosing the Right Methodologies, Tools and Standards', Information and Emerging Technologies (ICIET), 2010 International Conference on. IEEE, 2010.

[91] Rizwan, I., Masrah A. A. M., Aida, M. \& Nurfadhlina, M. S. (2013). An Analysis of Ontology Engineering Methodologies: A Literature Review. Research Journal of Applied Sciences, Engineering and Technology 6(16): 2993-3000

[92] Gavrilova, T. A., \& Leshcheva, I. A. (2015). Ontology design and individual cognitive peculiarities: A pilot study. Expert systems with Applications, 42(8), 3883-3892.

[93] Ibrahim, A. A., Abdul, A. A. G., Wan, N. W. R. \& Rodziah, A. (2014). A Comparative Study on Ontology Development Methodologies towards Building Semantic Conflicts Detection Ontology for Heterogeneous Web Services. Research Journal of Applied Sciences, Engineering and Technology 7(13): 2674-2679

[94] De Nicola, A., M., Missikoff \& Navigli, R. (2009) 'A Software Engineering Approach to Ontology Building' Inform. Syst., 34(2): 258-275.

[95] Del Águila, I. M., Palma, J., \& Túnez, S. (2014). Milestones in software engineering and knowledge engineering history: A comparative review. The Scientific World Journal, 2014.

[96] Jain, V., \& Singh, M. (2013). Ontology development and query retrieval using protégé tool. International Journal of Intelligent Systems and Applications, 9, 67-75.

[97] Rao, L., Mansingh, G., \& Osei-Bryson, K. M. (2012). Building ontology based knowledge maps to assist business process re-engineering. Decision Support Systems, 52(3), 577-589.

[98] Serna, E., \& Serna, A. (2014). Ontology for knowledge management in software maintenance. International Journal of Information Management, 34(5), 704-710.

[99] Tiffani J. B., Furuya E. Y., Gilad J. K., James J. C., \& Suzanne B. (2012). Development and evaluation of an ontology for guiding appropriate antibiotic prescribing', Journal of Biomedical Informatics 45 120-128
[100] Arp R. (2009) 'Practical steps in building a domain ontology, models and simulations 3: emergence, computation, and reality' Virginia: Charlottesville.

[101] Chen-Huei C., Fatemeh M. Z., \& Huimin Z. (2011). Ontology for Developing Web Sites for Natural Disaster Management: Methodology and Implementation. IEEE Transactions on Systems, Man, and Cybernetics-Part A: Systems and Humans, Vol. 41, No. 1

[102] Uschold, M \& Grüninger, M, (1996). Ontologies: principles methods and applications', KnowledgEngineeringReview11(2)93-137.

[103] Ceccaroni, L, Cortés, U \& Sánchez-Marré, M, (2000) 'WaWO - an ontology embedded into an environmental decision-support system for wastewater treatment plant management' Workshop on Applications of Ontologies and Problem solving Methods.14th European Conference on ArtificialIntelligence(ECAI'00)2-1-2-9

[104] Zheng, Y., He, Q., Qian, P. \& Li, Z. (2012). Construction of the Ontology-Based Agricultural Knowledge Management System. Journal of Integrative Agriculture, 11(5): 700-709

[105] Bonanci, R., Nabuco, O. F. \& Junior, I. P. (2016). Ontology models of the impacts of agriculture and climate changes on water resources: Scenarios on interoperability and information recovery' Future Generation Computer Systems. 54 (2016) 423-434

[106] Aree, T., Asanee, K., Supamard, P. \& Uamporn, V. (2009) 'Ontology Development: A Case Study for Thai Rice' Kasetsart J. (Nat. Sci.) $43: 594-604$

[107] Niu, J., \& Issa, R. R. (2015). Developing taxonomy for the domain ontology of construction contractual semantics: A case study on the AIA A201 document. Advanced Engineering Informatics, 29(3), 472-482.

[108] Gregor, D., Toral, S., Ariza, T., Barrero, F., Gregor, R., Rodas, J., \& Arzamendia, M. (2016). A methodology for structured ontology construction applied to intelligent transportation systems. Computer Standards \& Interfaces, 47, 108-119.

[109] Dutta, B., Chatterjee, U., \& Madalli, D. P. (2015). YAMO yet another methodology for large-scale faceted ontology construction. Journal of Knowledge Management, 19(1), 6-24.

[110]Zeb, J., Froese, T., \& Vanier, D. (2015). An ontologysupported asset information integrator system in infrastructure management. Built Environment Project and Asset Management, 5(4), 380-397.

[111] Mezghani, E., Exposito, E., \& Drira, K. (2016). A collaborative methodology for tacit knowledge management: Application to scientific research. Future Generation Computer Systems, 54, 450-455.

[112] Bautista-Zambrana, M. R. (2015). Methodologies to build ontologies for terminological purposes. Procedia-Social and Behavioral Sciences, 173, 264-269.

[113] Keet, C. M., Ławrynowicz, A., d'Amato, C., Kalousis, A., Nguyen, P., Palma, R., \& Hilario, M. (2015). The data mining OPtimization ontology. Journal of web semantics, 32, 43-53

[114] Rayyaan, R., Wang, Y., \& Kennon, R. (2014). Ontologybased interoperability solutions for textile supply chain. Advances in Manufacturing, 2(2), 97-105.

[115] Cristani, M., \& Cuel, R. (2005). A survey on ontology creation methodologies. International Journal on Semantic Web and Information Systems (IJSWIS), 1(2), 49-69.

[116] Sazedj, P. \& Pinto, H. S. (2005). Time to evaluate: Targeting annotation tools. In Proc. of Knowledge Markup and Semantic Annotation at ISWC 2005. 


\section{Authors' Profiles}

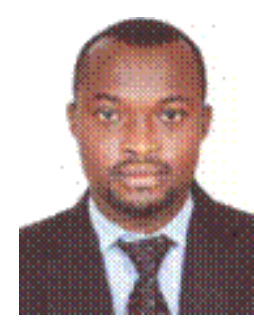

Enesi Femi Aminu presently lectures at Computer Science Department, Federal University of Technology, Minna, Nigeria and also a Ph.D student at the Department. Among courses teaching include Operating Systems, Database Design and Management, Object Oriented Programming, and Web Design. He obtained both his B.Sc and M.Sc degrees in Computer Science from University of Jos, Jos and Ahmadu Bello University, Zaria respectively. His current research interest is on Ontology Design and Semantic Search. Also a member of these professional bodies: Nigeria Computer Society (NCS) and International Association of Computer Science and Information Technology (IACSIT).

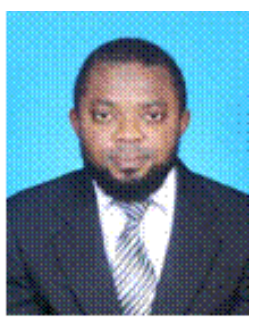

Dr. Ishaq Oyebisi Oyefolahan is currently an Associate Professor at the Department of Information and Media Technology, Federal University of Technology, Minna, Nigeria. Prior to joining his current department, he was an Assistant Professor at the Department of Information Systems, International Islamic University Malaysia. His fields of interest are Business Intelligence, Web and Mobile Applications Development, Utilization and Evaluation, Business-IT Alignment and Knowledge Management. He has published several technical papers in International, National journals and conferences.

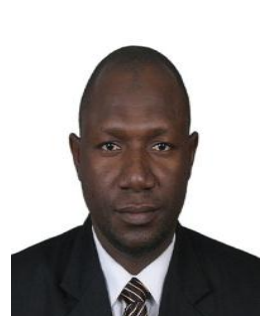

Muhammad Bashir Abdullahi received B.Tech (Honors) in Mathematics/Computer Science from Federal University of Technology, Minna-Nigeria, and $\mathrm{PhD}$ degree in Computer Science and Technology from Central South University, P. R. China. $\mathrm{He}$ is currently the head of Department of Computer Science at Federal University of Technology, Minna-Nigeria. His research interests are mainly in the areas of network and information security, Internet of Things, Machine learning, Big data Technology \& Cloud Computing.

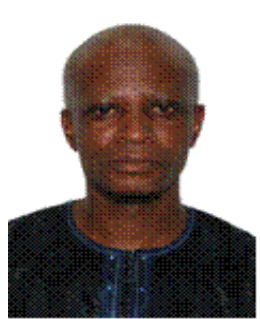

Dr. Muhammadu Tajudeen SALAUDEEN is currently a Senior Lecturer and Head, Department of Crop Production, Federal University of Technology, Minna, Nigeria. He holds a $\mathrm{PhD}$ Plant Pathology from the University of Ibadan, M. Sc Crop Protection from Ahmadu Bello University, Zaria, and B. (Agric) Tech. General Agriculture (First Class Honours) from the Federal University of Technology, Minna. He was a Research Fellow at the International Institute of Tropical Agriculture (IITA), Ibadan between 2009 and 2012 and a Visiting Scientist from 2013 - 2014 at the same Institute. $\mathrm{He}$ has received specialist training on Molecular Breeding and Analyses of Agricultural Research Data in the Netherlands (2012), Spain (2013 and 2014) and IITA, Ibadan. He won an International research grant in 2013 to investigate the status of Maize Lethal Necrosis Disease (MLND) in Nigeria. He conducts research on survey of plant viruses, plant virus diversity, virus host range and screening for resistance. He teaches Biostatistics, Crop Protection and Plant Pathology courses at undergraduate and postgraduate levels.

How to cite this paper: Enesi Femi Aminu, Ishaq Oyebisi Oyefolahan, Muhammad Bashir Abdullahi, Muhammadu Tajudeen Salaudeen, " A Review on Ontology Development Methodologies for Developing Ontological Knowledge Representation Systems for various Domains", International Journal of Information Engineering and Electronic Business(IJIEEB), Vol.12, No.2, pp. 28-39, 2020. DOI: 10.5815/ijieeb.2020.02.05 